Article

\title{
Exploring the Dynamic Coupling Relationship between Agricultural Economy and Agro-Ecological Environment in Semi-Arid Areas: A Case Study of Yulin, China
}

\author{
Xiuping Yang ${ }^{1}$, Dacheng Zhang ${ }^{1, *}$, Qiqi Jia ${ }^{2}$, Wentao Zhang ${ }^{3}$ and Tianyou Wang ${ }^{4}$ \\ 1 School of Economics and Management, Lanzhou University of Technology, Lanzhou 730050, China; \\ lecyxp@lut.cn \\ 2 School of Resource and Environmental Sciences, Wuhan University, Wuhan 430079, China; Jiaqqi@126.com \\ 3 School of Chemical Technology, Beijing University of Chemical Technology, Beijing 100029, China; \\ WentaoZhang@smail.nju.edu.cn \\ 4 School of Philosophy and Literature, Universidad Autónoma de Barcelona, 08193 Barcelona, Spain; \\ Tianyou.Wang@e-campus.uab.cat \\ * Correspondence: zhangdclut@outlook.com or zdc@lut.edu.cn
}

Received: 10 March 2019; Accepted: 11 April 2019; Published: 15 April 2019

\begin{abstract}
The rapid expansion of agricultural areas in semi-arid China over the past decades has aggravated the imbalance of the agroeconomy and agroecological environment. To further understand the coupling relationship between the two, this paper, taking Yulin as a case, develops an integrated index system for evaluation of the agricultural economy and the agroecological environment, and a model of the coupling coordination degree for evaluation of the dynamic coupling relationship between the two. Based on that, we have investigated the coupling coordination by comparing the differences of the development index of the two sub-systems at different periods. Subsequently, we further clarified the internal interaction and coupling relationship between the two sub-systems with a cross-impact analysis. The results suggested that the weights of ecological environmental conditions and agricultural development input are respectively0.5908 and 0.3570 . From 1997 to 2016, a high-level interactive coupling existed between the agroecological environment and agricultural economy, and the coupling coordination degree of the two sub-systems grew slowly. Overall, the degradation of the agroecological environment impeded the coordinated development of the agricultural economy and the level of coupling coordination improved from basic coordination in the beginning to superior coordination in the end. The agricultural economy grew rapidly, at the expense of the degradation of the agroecological environment. Furthermore, more attention should be paid to improving agricultural development input for promoting economic and ecological benefits, and coupling coordination degree of the two sub-systems. These findings are important for boosting sustainable development of the agricultural economy in semi-arid areas.
\end{abstract}

Keywords: agro-ecological environment; agricultural economy; semi-arid area; coupling coordinated degree model; Yulin

\section{Introduction}

Due to China's huge population, the area of arable land per capita is merely $0.09 \mathrm{hm}^{2}$, which is lower than the global average $\left(0.194 \mathrm{hm}^{2}\right)$. Feeding $20 \%$ of the world's population with only $7 \%$ of the world's arable land has witnessed China's agricultural development [1,2]. Owing to the continuous increasing population and living standards, the demand for food and other agricultural products has 
rapidly expanded. Nevertheless, increasing the food supply in the short run, by expanding agricultural land, is at the expense of a huge pressure on the ecological environment, especially in semi-arid areas, where the ecological environment is highly fragile. Due to the great seasonal and inter-annual variations in precipitation, frequent droughts, and insufficient water sources for irrigation, semi-arid areas are not suitable for large-scale crop cultivation [3-5]. However, considerable uncultivable land has been turned into farmland, owing to increasing demands for food, and resulting in reduced surface vegetation, soil erosion, and intensified desertification. However, farmers in the semi-arid areas of China and some other developing countries still maintain traditional agricultural production modes, which are characterized by small scale, low-level mechanization, and low output per unit. To increase grain output, people have no choice but to continuously expand the planting area and use chemical synthetic products, such as chemical fertilizers and pesticides, resulting in the reduction of biodiversity and further deterioration of the ecological environment.

As the foundation of agrarian economic development, the agro-ecological environment has been severely threatened by excessive agricultural expansion. The protection of agro-ecological environment globally was initiated with the proposal of sustainable development in the 1980s. In 1987, the "Our Common Future" report was launched, and it led to the reflection of the relationship between socio-economic development and the ecological environment [6]. Nowadays, sustainable agriculture has attracted great attention $[7,8]$, especially in relation to the damage and pollution of agricultural ecological environment caused by agricultural production activities, such as cultivated land expansion that has led to surface vegetation damage, aggravating desertification, and soil erosion [9-11]. Additionally, the abuse of fertilizers and pesticides has led to significantly reduced biodiversity [12-14]. Agricultural irrigation in semi-arid and arid regionscaused land salinization [15]. And scope promotion of improved crop varieties resulted in high and stable crop yields at the expense of reduced crop varieties and biodiversity $[16,17]$. As a result, some European countries have proposed measures to relieve the ecological problems in agricultural development. The Agricultural Environment Program leverages the diverse functions of agriculture to meet the needs of agricultural products, while protecting the agro-ecological environment and biodiversity, and environmentally-friendly agricultural development models, such as organic agriculture. Low-carbon agriculture have also been studied and applied [18-23]. These efforts have enriched our understanding of the relationship between agriculture and the ecological environment and facilitated agricultural sustainable development. Nevertheless, few studies of the interaction between the agro-ecological environment sub-system and the agriculture economy sub-system have been reported from a system coordination perspective.

The term "coupling", which refers to interaction between two or more systems or elements within a system [24,25], has been introduced into economic, ecologicaland social studies by some Chinese scholars. The term has been integrated into the concept of coordinated development consistent with sustainable development, it is now widely employed in the study of interaction and coordination between the ecological environment and urbanization [26-28]. However, the coupling model has seldomly been used in analysis of the relationship between agricultural economy and agro-ecological environment system. Wang (2009) investigated the coupling of the agricultural eco-economic system in the Zhifanggou watershed from low-level system to high-level system. The results indicated that the forestry and grass industry plays a key role in the agro-ecological economic system in loess hilly regions [29]. Lv et al. (2010) investigated the agricultural land ecosystem and socio-economic sub-system of the agricultural and pastoral areas in the Tarim River Basin, using the coupling degree model. The results indicated a strong interactive relationship between the two sub-systems [30]. Zhang et al. (2011) demonstrated that the coupling development of the agro-ecosystem is closely linked to domestic policies, indicating the significance of rational agriculture policy [31].

In this paper, we analyzed the dynamic coupling relationship between the agro-ecological environment and agricultural economy, in semi-arid areas, and the trend of their coordinated development. By establishing a coupling coordination degree model, the coupling and coordination characteristics of agro-ecological environment, and the agricultural economy were investigated. For the 
coordination relationship between sub-systems, which is a result of interactions between elements in different sub-systems, this study involved cross-impact analysis of factors between sub-systems, which is involved in few previous studies.

The structure of this article is as follows: Section 2 introduces the study area and methods and proposes the coupling coordination degree model. Section 3, involves research results and discussion and discusses the coupling and coordinated development relationship and development trend. The principal conclusions and counter-measure analysis are summarized in Section 4.

\section{Materials and Methods}

\subsection{Overview of the Study Area}

Yulin is located in the northern part of Shaanxi Province, China, which is adjacent to the Yellow River in the east, Ningxia and Gansu in the west, Mu Us Desert in the north, and Yan'an in the south. As shown in Figure 1, Yulin has a total area of $43,578 \mathrm{~km}^{2}$, of which $58 \%$ is loess area and $42 \%$ is exposed to desertification. Meanwhile, in the case of Yulin, the annual precipitation of Yulin is $450-500 \mathrm{~mm}$, while its evaporation capacity is $2000-2200 \mathrm{~mm}$. Low annual precipitation and huge evaporation capacity aggravate the aridness in the region, resulting in infertility of the land. Indeed, Yulin is a semi-arid area and the harsh natural environment has stimulated the development of an agricultural economy characterized by "half-agriculture and semi-pastoralism". In 2017, Yulin has a total population of 3.7 million and a total economic output of CNY 331.839 billion (GDP per capita CNY 97,811), among which agriculture, forestry, animal husbandry and fishery contribute CNY 29.221 billion, and the disposable income per capita of farmers is CNY 11,534 (increasing by 9\% a.n.) [32]. Owing to the rapidly increasing demand for food, dry farming and sheep feeding have rapidly developed and become the pillar industry of agricultural economic development in Yulin, enhancing the local economic development and the income of farmers.

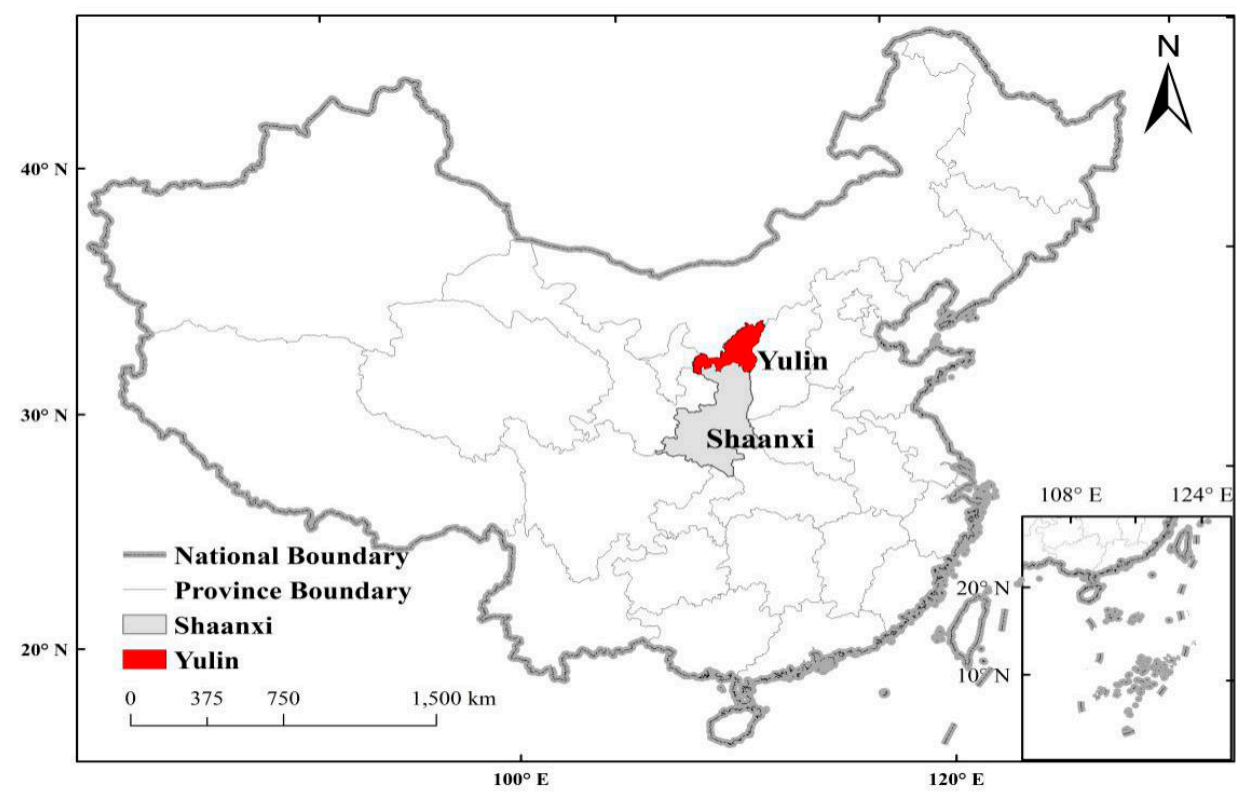

Figure 1. Geographical location of Yulin.

In semi-arid environments, dryland farming dominates in most cases, if irrigation coverage is not high. To increase the output, expanding the cultivating land area and the sheep population are the only choice, resulting in destroyed surface vegetation, intensified land desertification, and deteriorated agricultural ecological environment. To achieve sustainable development of the agricultural economy in Yulin, identifying the factors that limit the improvement of coordinated development is greatly urgent. This is carried out by investigating coupling development level, and evolution trend of agricultural 
economic development, and agro-ecological environment. Based on that, we aim to provide policy proposals for the ecological environment protection and agricultural economic development of Yulin. This study of the coordinated development of the agro-ecological environment and agroeconomy in Yulin can also provide references for development of similar areas located in the agro-pastoral transition zone.

\subsection{Data and Data Normalization}

Data of evaluation indicators from 1997 to 2016 in this study were obtained from statistical yearbook. Specifically, disaster areas of farm crops and the reservoir capacity data are from the Shaanxi Statistical Yearbook (1998-2017), while other data are from the Yulin Statistical Yearbook (1998-2017). For the data about disaster areas of farm crops in 1999 and 2002, the missing values were filled by averaging adjacent data.

To eliminate the dimensional difference of indicators, it is necessary to standardize the data for the agricultural ecological environment and the agricultural economic sub-systems. Also, the evaluation system of each sub-system consists of positive indicators (positively related) and negative indicators (negatively related). Moreover, 0.01 was added to the formula to avoid zero values. The computational process of indicator data converted to be dimensionless and comparable is as follows:

$$
\begin{aligned}
R_{i j} & =\left(x_{i j}-\min x_{j}\right) /\left(\max x_{j}-\min x_{j}\right)+0.01 \text { if } x_{i j} \text { is positive indicator } \\
R_{i j} & =\left(\max x_{j}-x_{i j}\right) /\left(\max x_{j}-\min x_{j}\right)+0.01 \text { if } x_{i j} \text { is negative indicator }
\end{aligned}
$$

where $x_{i j}$ represents the original value of indicator $j$ in year $i . R_{i j}$ is the normalized value of $x_{i j}$. max $x_{j}$ and $\min x_{j}$ are the maximum and minimum value of the index $j$. And the range of normalized value $R_{i j}$ is $[0,1]$.

\subsection{Methods}

\subsubsection{Evaluation Index System}

To quantify the coupling coordinated development relationship between agricultural economy and agro-ecological environment, we propose an integrated evaluation index system. The indicators comprise total amount indicators, indicators per capita, and indicators of the growth rate. The agro-ecological environment sub-system involves three primary indicators, including eco-environment condition, eco-environment pressure, and eco-environment treatment, and eleven secondary indicators, as shown in Table 1 . The agriculture economy sub-system involves four primary indicators, including agricultural development investment, agricultural output, agricultural productive structure and agricultural productive efficiency, and fifteen secondary indicators, as shown in Table 2.

\begin{tabular}{|c|c|c|c|c|}
\hline $\begin{array}{l}\text { First-Class } \\
\text { Indicators }\end{array}$ & Weight & Secondary Indicators & Units & Weight \\
\hline \multirow{5}{*}{$\begin{array}{l}\text { Eco-environment } \\
\text { condition }\end{array}$} & \multirow{5}{*}{0.5908} & Annual precipitation & $\mathrm{mm}$ & 0.0618 \\
\hline & & Amount of water resources per capita & cu.m/person & 0.1173 \\
\hline & & Forest coverage rate & $\%$ & 0.2332 \\
\hline & & Area of cultivated land per capita & hectares/person & 0.1147 \\
\hline & & Area of grassland per capita & hectares/person & 0.0638 \\
\hline \multirow{4}{*}{$\begin{array}{l}\text { Eco-environment } \\
\text { pressure }\end{array}$} & \multirow{4}{*}{0.2866} & Disaster areas of farm crops & $10^{3}$ hectares & 0.0705 \\
\hline & & Consumption of chemical fertilizers & kilograms/hectare & 0.0483 \\
\hline & & Plastic film consumption & kilograms/hectare & 0.1126 \\
\hline & & Pesticides consumption & kilograms/hectare & 0.0552 \\
\hline \multirow{2}{*}{$\begin{array}{l}\text { Eco-environment } \\
\text { treatment }\end{array}$} & \multirow{2}{*}{0.1226} & $\begin{array}{l}\text { Afforestation of barren hills and } \\
\text { wasteland area }\end{array}$ & hectares & 0.0794 \\
\hline & & Area of soil erosion control & $10^{3}$ hectares & 0.0432 \\
\hline
\end{tabular}

Table 1. Evaluation index system of the agro-ecological environment. 
Table 2. Evaluation index system of the agriculture economy.

\begin{tabular}{|c|c|c|c|c|}
\hline $\begin{array}{l}\text { First-Class } \\
\text { Indicators }\end{array}$ & Weight & Secondary Indicators & Units & Weight \\
\hline \multirow{5}{*}{$\begin{array}{c}\text { Agricultural } \\
\text { development input }\end{array}$} & \multirow{5}{*}{0.3570} & \multirow{5}{*}{$\begin{array}{c}\text { Proportion of agriculture population } \\
\text { Effectively imigated areas } \\
\text { Sown areas of farm crops per capita } \\
\text { Reservoir storage capacity per capita } \\
\text { Total agricultural machinery power } \\
\text { per capita }\end{array}$} & $\%$ & 0.0680 \\
\hline & & & $\%$ & 0.0418 \\
\hline & & & hectares/person & 0.1046 \\
\hline & & & cu.m/person & 0.0768 \\
\hline & & & Kilowatt/person & 0.0658 \\
\hline \multirow{4}{*}{ Agricultural output } & \multirow{4}{*}{0.2961} & $\begin{array}{l}\text { Gross output value of farming, } \\
\text { forestry, animal husbandry and } \\
\text { fishery per capita }\end{array}$ & $\mathrm{CNY/person}$ & 0.1142 \\
\hline & & Output of grain per capita & tons/person & 0.0344 \\
\hline & & Output of meat per capita & kilograms/person & 0.0671 \\
\hline & & Sheep stocked per capita & heads/person & 0.0804 \\
\hline \multirow{2}{*}{$\begin{array}{l}\text { Agricultural } \\
\text { productive } \\
\text { structure }\end{array}$} & \multirow{2}{*}{0.0652} & $\begin{array}{l}\text { Animal husbandry accounting for the } \\
\text { proportion of total agricultural output }\end{array}$ & $\%$ & 0.0265 \\
\hline & & $\begin{array}{l}\text { Farming accounting for the } \\
\text { proportion of total agricultural output }\end{array}$ & $\%$ & 0.0387 \\
\hline \multirow{4}{*}{$\begin{array}{l}\text { Agricultural } \\
\text { productive } \\
\text { efficiency }\end{array}$} & \multirow{4}{*}{0.2816} & $\begin{array}{l}\text { Growth rate of total } \\
\text { agricultural output }\end{array}$ & $\%$ & 0.0200 \\
\hline & & $\begin{array}{l}\text { Value added of farming accounting } \\
\text { for the proportion of total } \\
\text { agricultural output }\end{array}$ & $\%$ & 0.0206 \\
\hline & & $\begin{array}{l}\text { Agricultural output value per unit } \\
\text { area of farmland }\end{array}$ & $10^{4} \mathrm{CNY}$ & 0.1019 \\
\hline & & Rural per capita net income & $\mathrm{CNY}$ & 0.1391 \\
\hline
\end{tabular}

\subsubsection{Entropy Method Model}

In this study, the entropy method, which is an objective weighting method, is employed to determine the index weight to avoid the bias caused by subjective weighting [28,33]. Derived from thermodynamics, entropy has been introduced into information theory and widely used in the social economy and other fields. Herein, the degree of index variation is determined according to the size of each index entropy. A small entropy corresponds to a high variability, useful information, and great weight in the integrated evaluation. The calculation method of indicator weight is as follows:

The proportion of the indicator $j$ in year $i$ :

$$
P_{i j}=R_{i j} / \sum_{i=1}^{m} R_{i j}
$$

Information entropy of indicator $j$ :

$$
E_{j}=-K \sum_{i=1}^{m} P_{i j} \times \ln P_{i j} K=\frac{1}{\ln m}\left(0 \leq E_{j} \leq 1\right)
$$

Redundancy of information entropy of indicator $j$ :

$$
M_{j}=1-E_{j}
$$

Weight of the indicator $j$ :

$$
W_{j}=M_{j} / \sum_{j=1}^{n} M_{j}
$$

Evaluation of the single indicator:

$$
Y_{i j}=W_{j} \times x_{i j}
$$


Integrated evaluation value in year $i$ :

$$
X_{j}=\sum_{j=1}^{n} Y_{i j}
$$

where $P_{i j}$ is the proportion of the indicator $j$ in year $i$. $K$ represents the constant term determined by the number of years $m$. $E_{j}$ is information entropy of indicator $j . M_{j}$ is redundancy of information entropy of index $j . W_{j}$ is the Weight of the indicator $j . Y_{i j}$ represents evaluation of indicator $j$ in year $i$. $X_{j}$ is integrated evaluation value of indicator $j . n$ is the number of indicator.

According to Formula (1)-(8), the weights of first-class indices in agro-ecological environment sub-system and agriculture economy sub-system were determined using the entropy method. The weights of secondary indicators are calculated by summing up the weights of first-class indicator which it contains. The results are shown in Tables 1 and 2, respectively.

\subsubsection{Coupling Coordinated Degree Model}

Originating from physics, coupling reflects the interaction between two or more systems, or multiple forms of motion. The degree of interaction between different systems is denoted by the coupling degree [24].

The agrarian economy and the agro-ecological environment are closely related, interacting with each other. As shown in Figure 2, agricultural development is determined by factors concerning ecological environment including soil, light and heat, flora and fauna, and other factors like these. Also, natural disasters such as drought, floods, ecological degradation, and environmental pollution also limit the sustainable development of agriculture. Meanwhile, agricultural production is profoundly shaping the ecological environment. For instance, over-cultivation destroyed surface vegetation, thus aggravating soil erosion and desertification. The abuse of pesticides and fertilizers led to damages to the biodiversity. Once the agricultural activities exceeded the capacity of the ecological environment, severe ecological catastrophe may be observed. Therefore, agriculture and the ecological environment is a complex coupling system and their coordinated development is a pre-requisite for the sustainable development of regional agriculture.

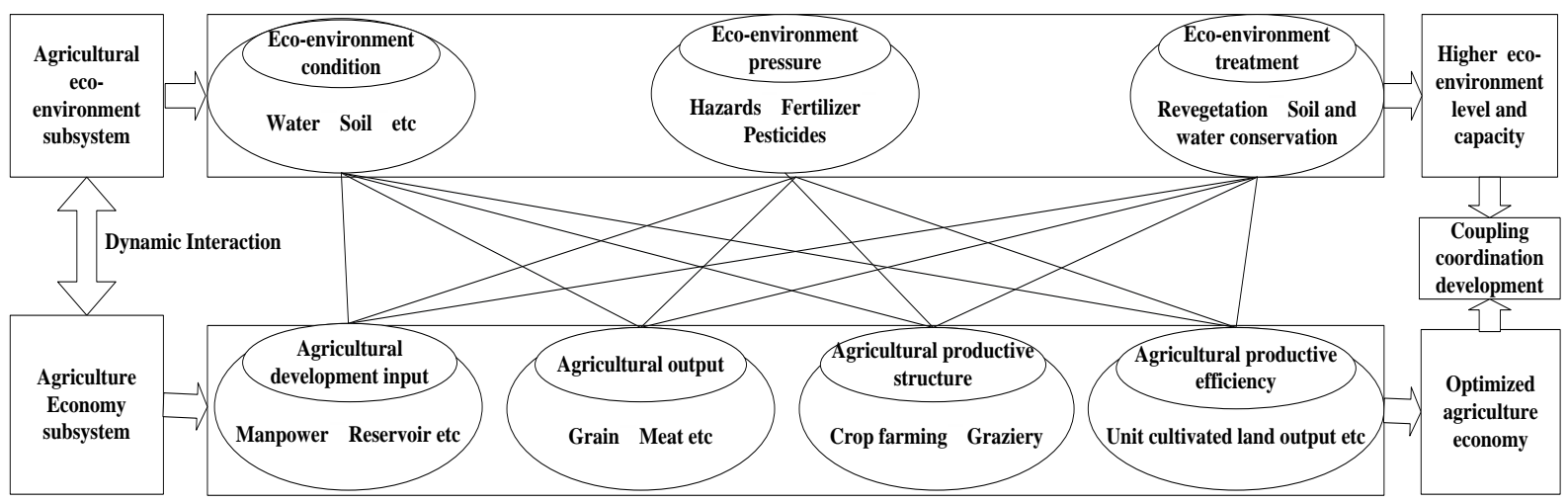

Figure 2. Coupling mechanism of agro-ecological environment sub-system and agriculture economy sub-system.

Based on the coupling model of physical capacity, the coupling degree model was established to evaluate the coupling relationship between agricultural economy and agro-ecological environment [28]. The calculation formula is as follows:

$$
C_{n}=\left\{\left(u_{1} \times u_{2} \times \cdots \times u_{n}\right) /\left[\prod\left(u_{i}+u_{j}\right) / n\right]^{n}\right\}^{\frac{1}{n}}
$$


Considering the consistency of the coupling relationship in different systems, the coupling degree model is applied to the study of the relationship between agricultural economy and agro-ecological environment development, and the coupling model of agricultural economy and agro-ecological environment is as follows:

$$
C=2 \sqrt{h(E) \times g(A)} /(h(E)+g(A))
$$

where, $C$ denotes the coupling degree, $h(E)$ denotes the development index of the agro-ecological environment, and $g(A)$ denotes the development index of the agricultural economy. Although the coupling degree can quantify the level of interplay between systems, this interactive effect is not necessarily the desired benign development relationship of coordination. The coupling coordinated degree can fully reflect the harmonious degree of interaction between elements and systems. Therefore, we develop a coupling coordinated degree model to evaluate the coordinated level of the coupling relationship between agricultural economy and agro-ecological environment, as follows:

$$
\begin{gathered}
T=\alpha h(E)+\beta g(A) \\
D=\sqrt{C \times T}
\end{gathered}
$$

where, $D$ represents the coupling coordinated degree, $T$ represents the integrated development index of agro-ecological environment and agriculture economy, $\alpha$ and $\beta$ are undetermined coefficients, reflecting the weight of the impacts of the agricultural economy and the agro-ecological environment on the integrated development level of the system. In this study, it is assumed that $\alpha$ and $\beta$ are equally crucial for the sustainable development of agriculture $(\alpha=\beta=1 / 2)$. According to the level of coupling development, the coupling degree can be divided into four stages [28], including the low-level coupling stage $([0.00,0.30))$, the antagonism coupling stage $([0.30,0.50))$, the transitional coupling stage $([0.50,0.80))$, and the high-level coupling stage $([0.80,1.00])$. Furthermore, the coupling coordinated degree was divided into seven concrete types and three development stage characteristics, as shown in Table 3.

\begin{tabular}{|c|c|c|c|}
\hline $\begin{array}{l}\text { Coupling Development } \\
\text { Stage }\end{array}$ & $\begin{array}{l}\text { Coupling Coordinated } \\
\text { Degree Interval }\end{array}$ & $\begin{array}{c}\text { Coupling Coordinated } \\
\text { Types }\end{array}$ & $\begin{array}{l}\text { Features of Stages of COUPLING } \\
\text { Coordination Development }\end{array}$ \\
\hline \multirow{2}{*}{$\begin{array}{l}\text { Coordinated } \\
\text { development }\end{array}$} & $0.80-1.00$ & Superior coordination & \multirow{7}{*}{$\begin{array}{c}\mathrm{h}(\mathrm{E})-\mathrm{g}(\mathrm{A})>0.1 \text { denotes favorable } \\
\text { eco-environment, lagged } \\
\text { agroeconomy } \\
\mathrm{g}(\mathrm{A})-\mathrm{h}(\mathrm{E})>0.1 \text { denotes fast-growing } \\
\text { agroeconomy, lagged } \\
\text { eco-environment } \\
-0.1 \leq \mathrm{h}(\mathrm{E})-\mathrm{g}(\mathrm{A}) \leq 0.1 \text { denotes } \\
\text { basically coordinated development }\end{array}$} \\
\hline & $0.70-0.79$ & $\begin{array}{l}\text { Intermediate } \\
\text { coordination }\end{array}$ & \\
\hline \multirow{3}{*}{$\begin{array}{c}\text { Transitional } \\
\text { development }\end{array}$} & $0.60-0.69$ & Elementary coordination & \\
\hline & $0.50-0.59$ & Bare coordination & \\
\hline & $0.40-0.49$ & Near imbalance & \\
\hline \multirow{2}{*}{$\begin{array}{c}\text { Degenerative } \\
\text { imbalanced development }\end{array}$} & $0.30-0.39$ & Slight imbalance & \\
\hline & $0.00-0.29$ & Serious imbalance & \\
\hline
\end{tabular}

Table 3. Stage division and stage development characteristics of coupling coordinated degree of agro-ecological environment and agriculture economy.

\section{Results and Discussion}

\subsection{Analysis of the Development Index of Agro-Ecological Environment and Agriculture Economy}

The weights of indicators in the agro-ecological environment and the agricultural economy were determined using data standardization and the entropy method. As shown in Tables 1 and 2, the agro-ecological environment sub-system involves three primary indicators. The impact weights of the eco-environment condition, eco-environment pressure, and ecological environment treatment were $0.5908,0.2866$ and 0.1226 , respectively. Therefore, the eco-environment condition is the dominant indicator for agro-ecological environment, and more attention should be paid by decision-makers on the natural conditions of agricultural development. The eco-environment pressure and eco-environment 
treatment weight have low impacts, demonstrating that the agricultural production activities and ecological environment control measures have slight effects on the ecological environment in Yulin area. This can be attributed to the fact that Yulin is located in a vast area of loess loss and the intensity of agricultural production is low. In addition, the environmental protection of scattered small areas in Yulin has limited impacts on the improvement of the overall environment in the short term. For secondary indicators, forest coverage (0.2332) has the greatest contribution on the agro-ecological environment, followed by water resources per capita (0.1173), arable land per capita (0.1147) and agricultural plastic film per hectare (0.1126). Therefore, the most effective way of facilitating agro-ecological environmental protection and sustainable development is by increasing forest and surface vegetation coverage, while reduce soil erosion [34].

As a critical factor in the agricultural economy, the agricultural development input is a primary indicator of the agricultural economy sub-system, with a weight of 0.3570 . The weights of agricultural output, agricultural productive efficiency, and agricultural productive structure are 0.2961, 0.2816, and 0.0652 , respectively. Among the secondary indicators, the weight of the sown areas of farm crops per capita is 0.1046 . The weight of the gross output value of the farming, the forestry, the animal husbandry and the fishery per capita is 0.1142 . The weight of the agricultural output per unit of cultivated land is 0.1019 . The weight of the income per capita is 0.1391 . The weight of the effective irrigation rate is 0.0418 . The weight of reservoir capacity per capita is 0.0768 , and the weight of agricultural machinery total power per capita is 0.0658 . Thus, the agricultural infrastructure is not a dominant factor for the development of Yulin's agriculture. Instead, the size of crop planting area has been a dominating factor for the agricultural economic output. This can be attributed to the ravined topography and terrain in the loess plateau, which hindered the application of agricultural machinery and irrigation facilities. Indeed, the agricultural production in Yulin still remains in the traditional model and the prosperity of animal husbandry reduces its dependence on crop planting. Therefore, sustainable development of the agricultural economy in Yulin mainly relies on increasing investment in agricultural infrastructure and exploiting land resources.

As shown in Figure 3, the development index and three primary indicators for the agro-ecological environment fluctuated in 1997-2016. Specifically, the development index showed a W-shape trend: it declined in 1997-2006, increased in 2006-2011, decreased drastically in 2011-2013, and then increased continuously in 2013-2016. However, the integrated development level of the agro-ecological environment in 2016 was still lower than that in 1997, indicating that the agricultural ecological environment has deteriorated over the past two decades. The trend of eco-environmental condition is consistent with that of integrated development index of the agro-ecological environment, and they are positively correlated at the $1 \%$ significance level, while the ecological environment pressure decreased continuously, indicating negligible impacts of the agricultural production activities on the ecological environment. This is not perfectly consistent with previous studies. It can be attributed to the dominant role of small-scale operation on a family basis in Yulin, which is different from the "high input, high output" model in other regions, especially America and Europe [35,36]. Although the eco-environment management remained at a low level during the past two decades, advances in soil erosion control and greening projects have led to an improvement in the ecological environment conditions since 2005 [37]. Also, the overall quality of the ecological environment has improved, demonstrating the effectiveness of eco-environmental management measures, such as returning farmland to forests over the long term. 


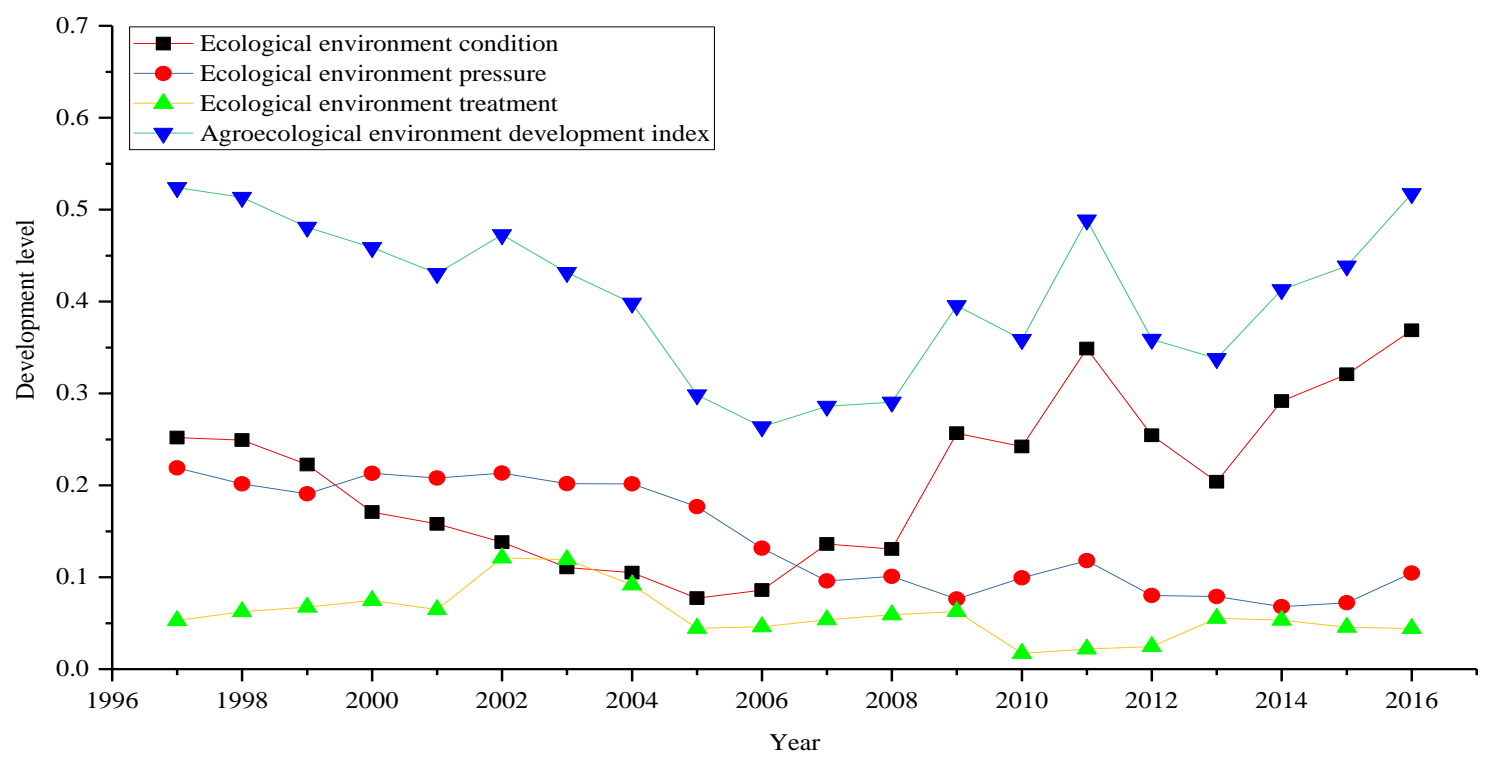

Figure 3. Evolutionary trend of development index of agro-ecological environment.

Figure 4 depicts the development trend of the agricultural economy and the four primary indicators during the study period. The development index of the agricultural economy increased, which reflected the integrated development level of the four primary indicators. The agricultural productive structure remained unchanged in 1997-2016, indicating no changes in the proportion of planting and animal husbandry in the agricultural production structure and the negligible effects on the development level of agricultural economy. The trends of the three primary indicators, including the agricultural development input, agricultural output, and agricultural production efficiency, were highly consistent. At the significance level of $1 \%$, the three primary indicators were positively related. According to the correlation tests, the agricultural output and the agricultural production efficiency were proportional to the agricultural resources input. Also, the development index of the agricultural economy increased slightly in 1996-1997, and decreased drastically since 2003. Meanwhile, the agricultural development input declined in 1996-2003, resulting in slow improvement of agricultural output and agricultural production efficiency. In 2013-2016, while the agricultural input increased significantly, the agricultural output and the agricultural productive efficiency increased accordingly. As a result, the development index for the agricultural economy was improved in the past two decades.

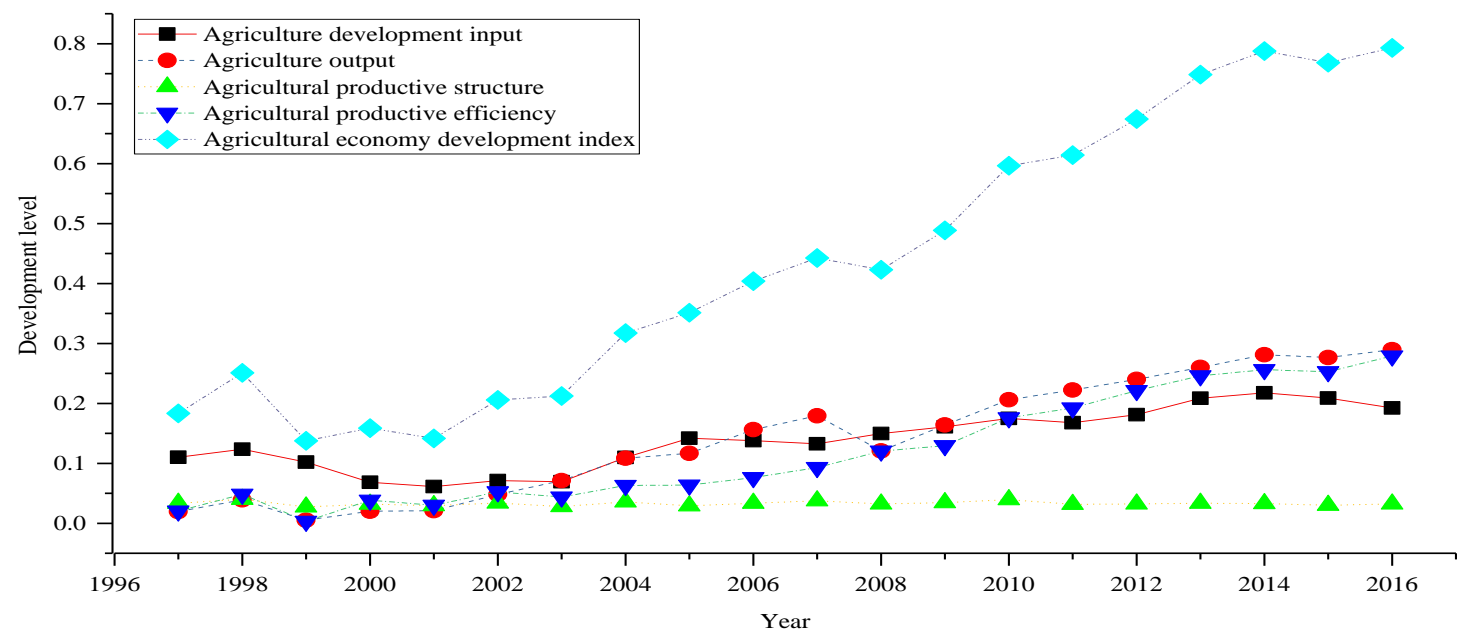

Figure 4. Evolutionary trend of development index of agriculture economy. 
As shown in Table 4, the pearson correlation coefficient was employed to describe the reciprocal effect of the elements of the agro-ecological environment and the agricultural economy system. Except for the agricultural production structure, all factors are significantly correlated with each other, indicating a close relationship and interactions of the elements in the agricultural ecological environment sub-system and the agricultural economy sub-system. Further quantitative analysis on the elements revealed correlation coefficients $(>0.8)$. As shown in Figure 5, the agricultural input and the ecological environment pressure, and the agricultural output and the ecological environment were well fitted. In other words, these factors are closely related to each other, which favors the understanding of the interaction mechanism between the agro-ecological environment and the agricultural economic sub-system in semi-arid regions.

Table 4. Correlation coefficient of agro-ecological environment sub-system and agriculture economy sub-system.

\begin{tabular}{|c|c|c|c|c|c|c|c|c|}
\hline & & EEC & EEP & EET & ADI & AO & APS & APE \\
\hline \multirow[t]{2}{*}{ EEC } & $\begin{array}{c}\text { Pearson } \\
\text { correlation }\end{array}$ & 1 & & & & & & \\
\hline & Significance & & & & & & & \\
\hline \multirow[t]{2}{*}{ EEP } & $\begin{array}{c}\text { Pearson } \\
\text { correlation }\end{array}$ & $-0.449^{*}$ & 1 & & & & & \\
\hline & Significance & 0.047 & & & & & & \\
\hline \multirow{2}{*}{ EET } & $\begin{array}{l}\text { Pearson } \\
\text { correlation }\end{array}$ & $-0.505^{*}$ & $0.602^{* *}$ & 1 & & & & \\
\hline & Significance & 0.023 & 0.005 & & & & & \\
\hline \multirow[t]{2}{*}{ ADI } & $\begin{array}{l}\text { Pearson } \\
\text { correlation }\end{array}$ & $0.590^{* *}$ & $-0.891^{* *}$ & $-0.678^{* *}$ & 1 & & & \\
\hline & Significance & 0.006 & 0.000 & 0.001 & & & & \\
\hline \multirow[t]{2}{*}{$\mathrm{AO}$} & $\begin{array}{c}\text { Pearson } \\
\text { correlation }\end{array}$ & $0.518^{*}$ & $-0.898^{* *}$ & $-0.562^{* *}$ & $0.917^{* *}$ & 1 & & \\
\hline & Significance & 0.019 & 0.000 & 0.010 & 0.000 & & & \\
\hline \multirow[t]{2}{*}{ APS } & $\begin{array}{c}\text { Pearson } \\
\text { correlation }\end{array}$ & 0.058 & -0.154 & -0.180 & 0.173 & 0.123 & 1 & \\
\hline & Significance & 0.810 & 0.516 & 0.447 & 0.465 & 0.605 & & \\
\hline \multirow[t]{2}{*}{$\mathrm{APE}$} & $\begin{array}{c}\text { Pearson } \\
\text { correlation }\end{array}$ & $0.653^{* *}$ & $-0.854^{* *}$ & $-0.537^{*}$ & $0.908^{* *}$ & $0.959^{* *}$ & 0.078 & 1 \\
\hline & Significance & 0.002 & 0.000 & 0.015 & 0.000 & 0.000 & 0.743 & \\
\hline
\end{tabular}

* The correlation was significant at the significance level of 0.05 (two-tailed test). ${ }^{* *}$ The correlation was significant at the significance level of 0.01 (two-tailed test).

EEC, EEP, EET, ADI, AO, APS, APE denote eco-environment condition, eco-environment pressure, eco-environment treatment, agricultural development input, agricultural output, agricultural productive structure, and agricultural productive efficiency, respectively. 

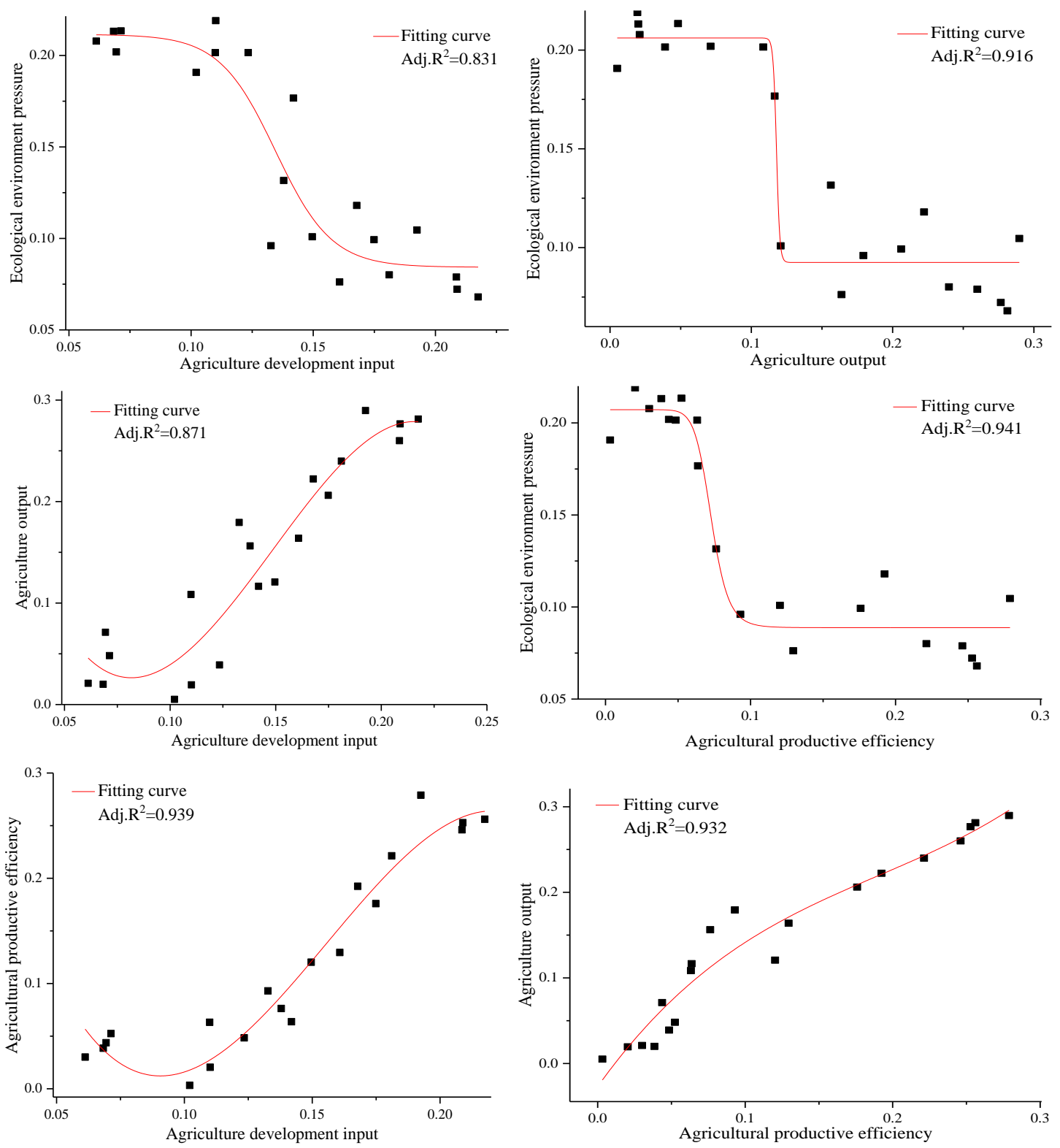

Figure 5. Curve fitting of the interactive relationship between elements of agro-ecological environment sub-system and elements of agriculture economy sub-system where correlation coefficient of these elements is greater than 0.8 .

\subsection{Analysis of Coupling Coordinated Degree of the Agro-Ecological Environment and Agriculture Economy}

The coupling degree and integrated development index of the two sub-systems were calculated on the basis of the development index of the agro-ecological environment and agricultural economy. As shown in Figure 6, the integrated development index was determined by the same weight coefficients for the development indices of agro-ecological environment and agricultural economy, respectively. Its trend is consistent with that of the development index of agricultural economy and the coupling coordinated degree of the two sub-systems. The integrated development level of agro-ecological environment and agricultural economy in Yulin remained unchanged in 1997-2008 and was significantly enhanced in 2008-2016. Obviously, an inflection point was observed in 2008. The coupling degree, which reflected the interaction between agro-ecological environment and agricultural economy, remained high $(>0.8)$, indicating mutual interaction of the two sub-systems of agro-ecological environment and agricultural economy of Yulin. 


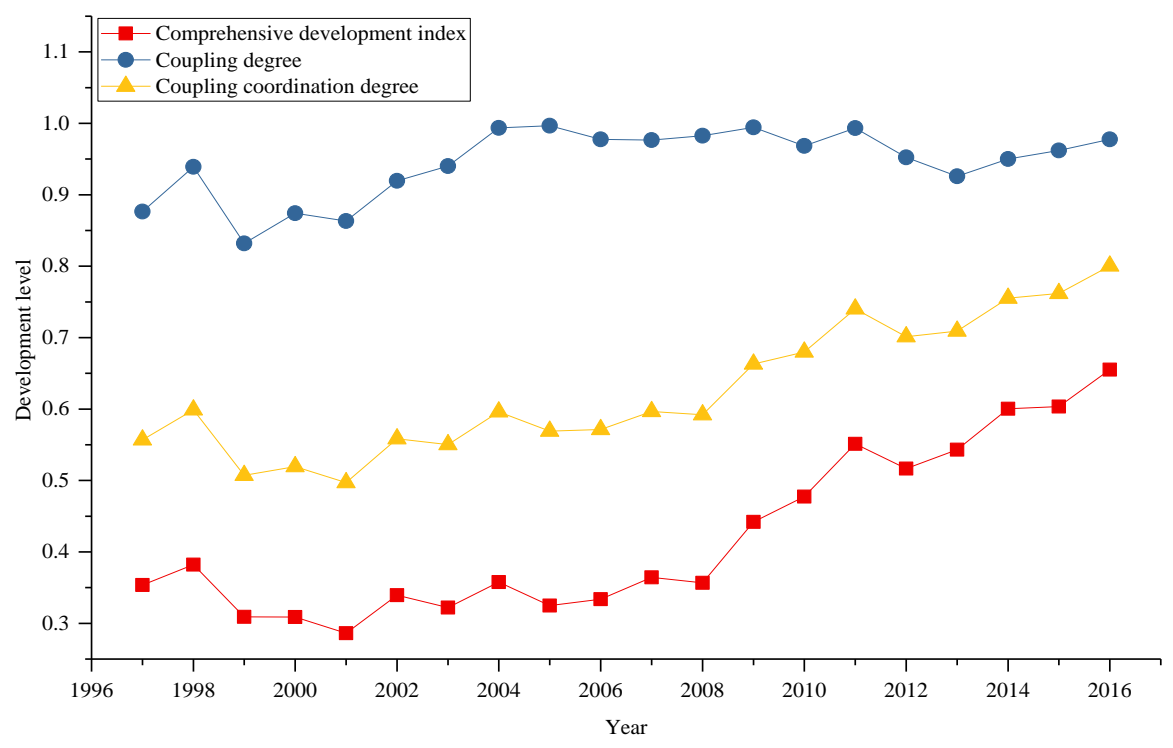

Figure 6. Development trend of agro-ecological environment and agricultural economic comprehensive development index, coupling degree and coupling coordination degree in Yulin City.

Owing to the interaction between agro-ecological environment and agricultural economy of the semi-arid region, the coupling coordinated degree of agro-ecological environment and agricultural economy increased with fluctuations as shown in Figure 6. Furthermore, according to the size of coupling coordinated degree and the integrated development index of agro-ecological environment and agriculture economy in Yulin, the coupling coordinated types and features of stages of coupling coordination development were displayed in Figures 7 and 8, using geographic information system (GIS) technology, then the variation of the coupling coordination degree can be divided into six stages:

(1) 1997-1998: The coupling coordinated degree of the agro-ecological environment and the agricultural economy had been significantly improved, but Yulin was characterized by an appropriate agro-ecological environment and slow agricultural economy development. The development index of the agricultural ecological environment declined, while the development level of the agricultural economy increased, demonstrating the dominant effect of increase in the agricultural productive input, especially the expansion of cultivated land, on the agricultural output, although the ecological environment was also affected by agricultural activities.

(2) 1998-2001: The coupling coordination level experienced a sharp decline at this stage, and Yulin was still characterized by a good agro-ecological environment and a slow agricultural economic development. Herein, the integrated development level of agro-ecological environment descended and the development index of agricultural economy dropped drastically to a low level. This can be attributed to reduced surface vegetation caused by the excessive expansion of crop planting area in 1997-1998. In addition, precipitation in 1998 was concentrated, resulting in floods and intensified soil erosion.

(3) 2001-2008: The coupling coordination degree increased slightly with slight fluctuations at this stage. The agro-ecological environment and the agricultural economy went through a "good ecological environment, lagged agricultural economy—basic coordinated development-fast-growing agricultural economy, poor agro-ecological environment" cycle. This transition is a consequence of the continuous decline of the development level of the ecological environment in 1997-2006. Meanwhile, the agricultural economy experienced a rapid growth and a turning point appeared in 2008 as the integrated development index of agricultural economy surpassed that of the agro-ecological environment. In other words, the development of the agricultural economy in this period was partly at the expense of deteriorating ecological environment. As the crop-planting area expanded, the soil erosion and the loss of surface soil fertility had been intensified due to the absence of effective 
measures, resulting in no improvements in the coupling coordinated level of the agro-ecological environment and agricultural economy.

(4) 2008-2011: The integrated development of agro-ecological environment and agricultural economy experienced a significant improvement, resulting in an improvement in the coupling coordinated degree of the two sub-systems. Nevertheless, the synthetical development level of agricultural economy was still higher than that of the agro-ecological environment. Yulin was characterized by "fast-growing agricultural economy, poor agro-ecological environment". The coordinated development level at this stage was heavily dependent on the improvement of ecological environment conditions, especially the increasing forest coverage and relatively stable annual precipitation.

(5) 2011-2012: The trend of the coupling coordinated degree of the agro-ecological environment and the agricultural economy was reversed in 2011, due to a sharp decline of the development index of the agro-ecological environment. In other words, the poor ecological environment limited the coordinated development. Also, the reduction in water resources per capita led to a deterioration of the ecological environment, which in turn led to decline in the coupling coordinated degree of the agro-ecological environment and agricultural economy.

(6) 2012-2016: The coordination level remained increasing at this stage and was optimized in 2016, as shown in Figure 7. The rapidly improving development index of the agricultural economy still preceded the poor ecological environment, and its growth derived from the improvement of eco-environmental conditions and the reinforcement of eco-environmental management in 2012-2013. Meanwhile, the level of agricultural development input dropped, due to the decrease of the agricultural population and the decline of effective irrigation rate, resulting in low increasing rate of the development index of the agricultural economy in 2014-2016. This can be ascribed to the shifting of agricultural population to the secondary and tertiary industries.

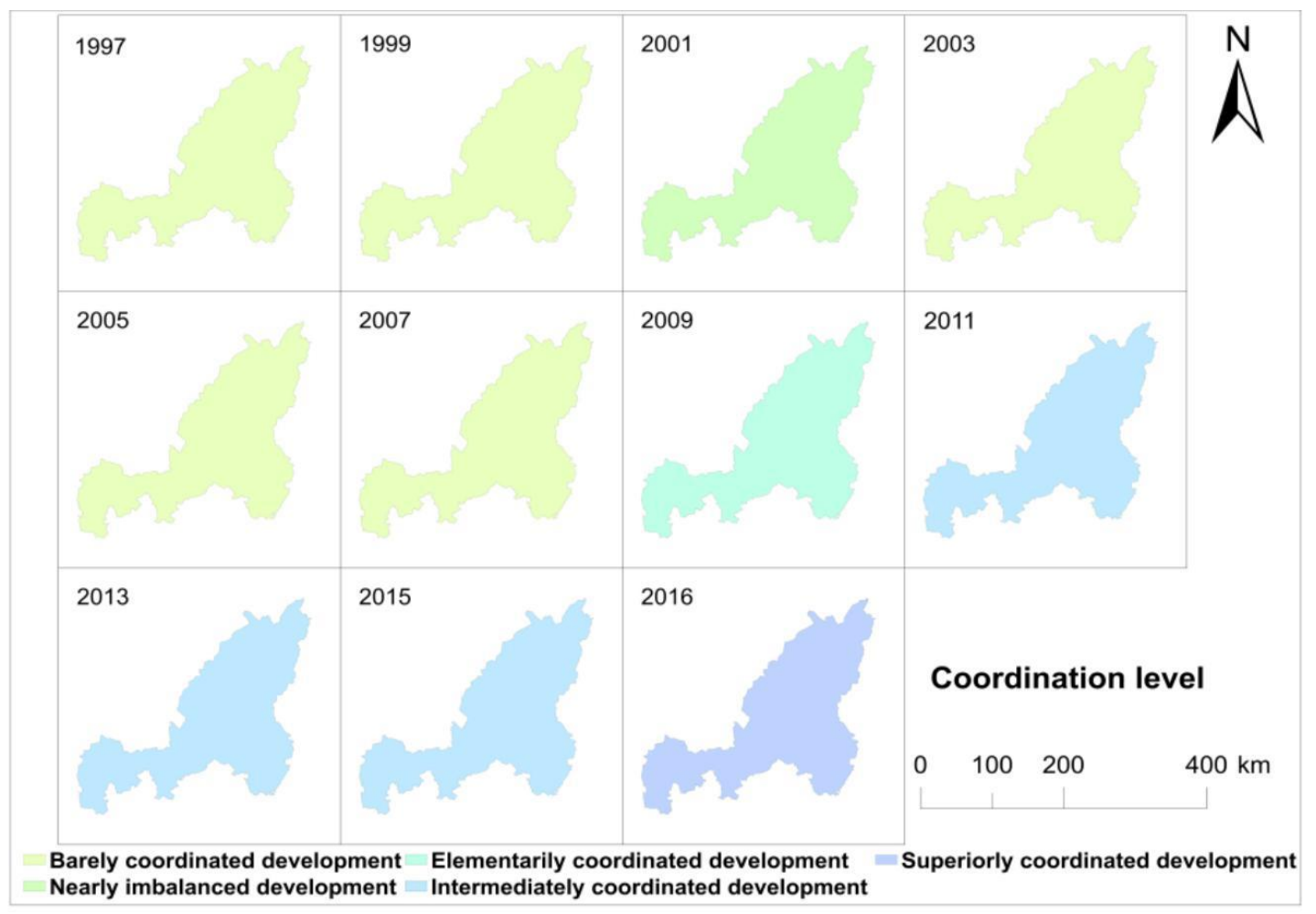

Figure 7. Evaluation of coupling coordinated types between agro-ecological environment and agriculture economy in Yulin. 


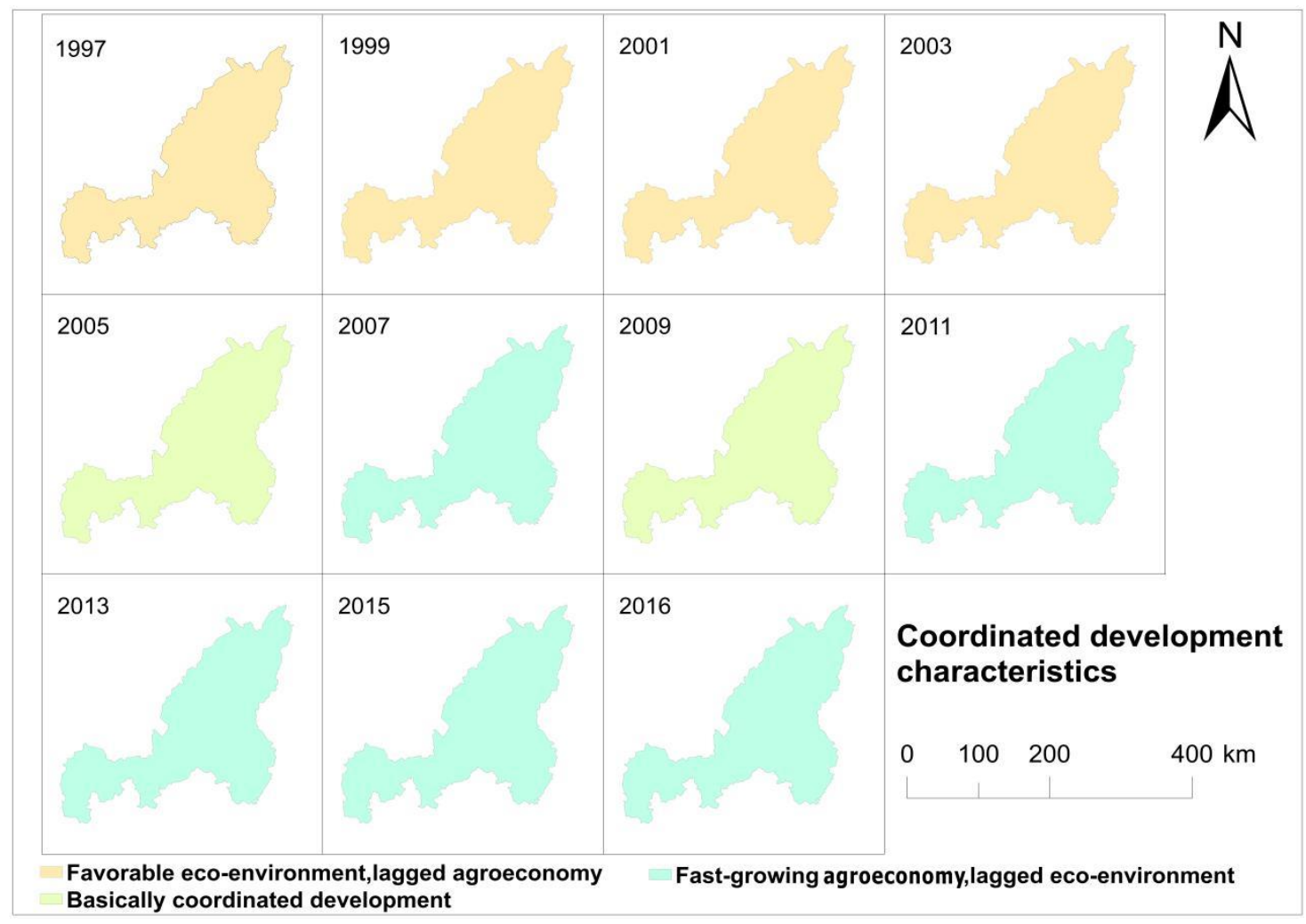

Figure 8. Evaluation of coupling coordinated development characteristics between agro-ecological environment and agriculture economy in Yulin.

In summary, the strong interaction between agro-ecological environment and agricultural economy has a significant effect on local agriculture. The overall coupling coordination degree increased and the coupling coordinated types changed from reluctant coordination to high-quality coordination (Figure 7), with characteristics of fast-growing agricultural economy and poor ecological environment (Figure 8). Additionally, Yulin has a significantly varying annual precipitation, low surface vegetation coverage, and severe soil erosion on the Loess Plateau. Previously, agricultural output was mainly enhanced by expanding the planting area, which may lead to deterioration of the ecological environment, thus limiting the coordinated development of the agro-ecological environment and the agricultural economy. Therefore, a long-term project of returning farmland to forests and grasslands, rather than short-term ecological environment control measures, is needed. The expansion of the agricultural production scale can increase agricultural economic output and farmer income at no expense to the agricultural ecological environment, thus improving the integrated development of agricultural economy and achieving the coordinated development of agricultural economy and agricultural ecological environment. Therefore, an overall understanding of the coordinated development of the agro-ecological environment and agricultural economy is necessary for sustainable development of agriculture in Yulin.

\section{Conclusions}

This research reveals an intrinsic relevance and coordination relationship between the agro-ecological environment and the agricultural economy sub-system. This study serves as a reference to fully understanding of the agro-ecological environment and agricultural economy, thus facilitating sustainable development of agriculture in semi-arid areas.

Based on the physical coupling model, we propose a coupling coordinated degree model to evaluate the coordinated development level of the agro-ecological environment and the agricultural economy in Yulin, and the trend of the interaction of the two sub-systems, as well as the key 
factors affecting the agricultural coordinated development of Yulin in 1997-2016. The weights of the agro-ecological environment and the agricultural economic indicators were determined using the entropy weight method. As the forest coverage was demonstrated to be the dominant factor in the agro-ecological environment sub-system in Yulin, returning farmland to forest and surface vegetation protection plays a key role in the improvement of ecological environment. Meanwhile, the overall development level of agro-ecological environment and the development level of ecological environment condition are positively correlated. The fragile natural environment leads to a $\mathrm{W}$-shape trend of the development index of agro-ecological environment in Yulin. In the agricultural economy sub-system, the net income per capita, the output value per unit cultivated land, the agricultural output per capita and the crop planting area per capita have weights greater than 0.1, while the weights of the reservoir capacity per capita and agricultural machinery total power per capita are low, indicating that the agricultural development in semi-arid areas depends on the expansion of crop planting area. However, insufficient investment in agricultural infrastructure, especially the absence of abundant farmland water conservancy facilities, reduces drought resistance.

The coupling degree of the agro-ecological environment and agricultural economy is a high-level coupling, reflecting the high degree of interactivity between the two sub-systems. This is the basic premise for further analysis of the level of coupling coordinated development. During the research period, agricultural development is constrained by the ecological environment. Obviously, the lagged development of agro-ecological environment has led to a slow increase in the level of coordinated development. Only in 2016, superior coordination has been achieved, and the level of coordinated development in other years is low.

Based on the analysis of the evolutionary trajectory and influence factors of the coordinated development of the agro-ecological environment and agricultural economy over the past two decades, we put forward the following four suggestions: Firstly, increasing the construction of agricultural infrastructure and enhancing the ability of the resistance to ecological environment disturbances, and maintaining the stability of agricultural output; secondly, adjusting the structure of agricultural production, getting rid of dependence on a single crop, appropriately expanding the development of animal husbandry, and reducing the damage to surface vegetation caused by land reclamation; thirdly, increasing investment in agricultural science and technology and cultivating drought-tolerant crop varieties, improving farmland management and unit farmland output; fourthly, increasing soil erosion control through long-term systematic returning farmland to forestry project, reducing the loss of surface soil fertility, and improving ecological environment carrying capacity. These measures can promote sustainable development of agriculture in Yulin City and other semi-arid areas.

Future research can further analyze the interactive coupling mechanism between agricultural economy and agroecological environment. More natural and economic factors, such as land desertification area, energy consumption per unit of agricultural output, can be considered. Meanwhile, the spatial study area can be extended to the whole agro-pastoral zone in China, and further deepen the coupling relationship between agricultural economy and agro-ecological environment. In addition, the theoretical framework and mathematical model, built in this paper, can be used to analyze the coupling coordinated degree of the agricultural ecological environment and agricultural economy of inland oasis, making cross-regional comparative analysis, such as oasis agriculture in the Tarim River Basin of China and oasis agriculture in the Amu River Basin of Central Asia.

Additionally, the coupled model is a means for quantitative analysis of coordinated development and has some intrinsic limitations. Indeed, a universal method for all situations is never possible, due to variations in the regional environment. Therefore, the cross-effects of the elements in the agro-ecological environment and the agricultural economy were investigated. This is done by combining the mathematical statistical method and the coupling coordinated model to fully understand the intrinsic relations and interactions of the coordinated development of the agro-ecological environment and agricultural economy system. 
Author Contributions: Conceptualization, T.W.; Methodology, D.Z.; Software, Q.J.; Data curation, W.Z.; Formal analysis, D.Z.; Writing-original draft preparation, D.Z.; Writing—review and editing, X.Y.; Funding acquisition, X.Y.

Funding: The National Natural Science Youth Fund Project of China (Grant No. 41501597). The Ministry of Education Humanities and Social Sciences General Project (Grant No. 11XJC630016). The Social Science Planning Project of Lanzhou City (Grant No. 16-007E). The Social Science Planning Key Project of Lanzhou City (Grant No. 14-038E). Lanzhou University of Technology Student Science and Technology Innovation Fund (Grant No. KC2018ZS075; Grant No. JG2018ZS005).

Acknowledgments: The authors express their gratitude to the four anonymous reviewers for their constructive comments and suggestions.

Conflicts of Interest: The authors declare no conflict of interest.

\section{References}

1. Chen, J. Rapid urbanization in china: A real challenge to soil protection and food security. Catena 2007, 69, 1-15. [CrossRef]

2. Zhang, J. China's success in increasing per capita food production. J. Exp. Bot. 2011, 62, 3707-3711. [CrossRef] [PubMed]

3. Montecinos, S.; Gutiérrez, J.R.; López-Cortés, F.; López, D. Climatic characteristics of the semi-arid coquimbo region in chile. J. Arid Environ. 2016, 126, 7-11. [CrossRef]

4. Xia, J.; Ning, L.; Wang, Q.; Chen, J.; Wan, L.; Hong, S. Vulnerability of and risk to water resources in arid and semi-arid regions of west china under a scenario of climate change. Clim. Chang. 2017, 144, 549-563. [CrossRef]

5. Yin, Y.; Ma, D.; Wu, S. Enlargement of the semi-arid region in china from 1961 to 2010. Clim. Dyn. 2019, 52, 509-521. [CrossRef]

6. Burton, I. Report on reports: Our common future. Environ. Sci. Policy Sustain. Dev. 1987, 29, 25-29. [CrossRef]

7. Kass, D.C.L. Agroecology: The science of sustainable agriculture. Agrofor. Syst. 1996, 35, 111-115. [CrossRef]

8. Singh, J.S.; Pandey, V.C.; Singh, D.P. Efficient soil microorganisms: A new dimension for sustainable agriculture and environmental development. Agric. Ecosyst. Environ. 2011, 140, 339-353. [CrossRef]

9. Kairis, O.; Kosmas, C.; Karavitis, C.; Ritsema, C.; Salvati, L.; Acikalin, S.; Alcalá, M.; Alfama, P.; Atlhopheng, J.; Barrera, J.; et al. Evaluation and selection of indicators for land degradation and desertification monitoring: Types of degradation, causes, and implications for management. Environ. Manag. 2014, 54, 971-982. [CrossRef]

10. Kateb, H.E.; Zhang, H.; Zhang, P.; Mosandl, R. Soil erosion and surface runoff on different vegetation covers and slope gradients: A field experiment in southern shaanxi province, China. Catena 2013, 105, 1-10. [CrossRef]

11. Silvestri, N.; Pistocchi, C.; Antichi, D. Soil and nutrient losses in a flat land-reclamation district of central italy. Land Degrad. Dev. 2017, 28, 638-647. [CrossRef]

12. Mclaughlin, A.; Mineau, P. The impact of agricultural practices on biodiversity. Agric. Ecosyst. Environ. 1995, 55, 201-212. [CrossRef]

13. Baker, N.J.; Bancroft, B.A.; Garcia, T.S. A meta-analysis of the effects of pesticides and fertilizers on survival and growth of amphibians. Sci. Total Environ. 2013, 449, 150-156. [CrossRef] [PubMed]

14. Schmitz, J.; Hahn, M.; Brühl, C.A. Agrochemicals in field margins-An experimental field study to assess the impacts of pesticides and fertilizers on a natural plant community. Agric. Ecosyst. Environ. 2014, 193, 60-69. [CrossRef]

15. Mora, J.L.; Herrero, J.; Weindorf, D.C. Multivariate analysis of soil salination-desalination in a semi-arid irrigated district of spain. Geoderma 2017, 291, 1-10. [CrossRef]

16. Banks, J.E. Divided culture: Integrating agriculture and conservation biology. Front. Ecol. Environ. 2004, 2, 537-545. [CrossRef]

17. D'Acunto, L.; Andrade, J.F.; Poggio, S.L.; Semmartin, M. Diversifying crop rotation increased metabolic soil diversity and activity of the microbial community. Agric. Ecosyst. Environ. 2018, 257, 159-164. [CrossRef]

18. Eva, K.; David, K.; Felix, H.; Bernhard, S. Effectiveness of the swiss agri-environment scheme in promoting biodiversity. J. Appl. Ecol. 2006, 43, 120-127. 
19. Bright, J.A.; Morris, A.J.; Field, R.H.; Cooke, A.I.; Grice, P.V.; Walker, L.K.; Fern, J.; Peach, W.J. Higher-tier agri-environment scheme enhances breeding densities of some priority farmland birds in england. Agric. Ecosyst. Environ. 2015, 203, 69-79. [CrossRef]

20. Batáry, P.; Dicks, L.V.; Kleijn, D.; Sutherland, W.J. The role of agri-environment schemes in conservation and environmental management. Conserv. Biol. 2015, 29, 1006-1016. [CrossRef]

21. Crowder, D.W.; Northfield, T.D.; Strand, M.R.; Snyder, W.E. Organic agriculture promotes evenness and natural pest control. Nature 2010, 466, 109-112. [CrossRef] [PubMed]

22. Dinis, I.; Ortolani, L.; Bocci, R.; Brites, C. Organic agriculture values and practices in portugal and italy. Agric. Syst. 2015, 136, 39-45. [CrossRef]

23. Fogarassy, C.; Nabradi, A. Proposals for low-carbon agriculture production strategies between 2020 and 2030 in hungary. Appl. Stud. Agribus. Commer. (APSTRACT) 2015, 9, 5-16.

24. Fang, C.; Jing, W. A theoretical analysis of interactive coercing effects between urbanization and eco-environment. Chin. Geogr. Sci. 2013, 23, 147-162. [CrossRef]

25. Liu, Y.B.; Li, R.D.; Song, X.F. Analysis of Coupling degrees of urbanization and ecological environment in China. J. Nat. Resour. 2005, 20, 105-112. (In Chinese)

26. Wang, S.J.; Ma, H.; Zhao, Y.B. Exploring the relationship between urbanization and the eco-environment-A case study of beijing-tianjin-hebei region. Ecol. Indic. 2014, 45, 171-183. [CrossRef]

27. Zhao, Y.; Wang, S.; Zhou, C. Understanding the relation between urbanization and the eco-environ ment in china's yangtze river delta using an improved ekc model and coupling analysis. Sci. Total Environ. 2016, 571, 862-875. [CrossRef] [PubMed]

28. He, J.; Wang, S.; Liu, Y.; Ma, H.; Liu, Q. Examining the relationship between urbanization and the eco-environment using a coupling analysis: Case study of shanghai, China. Ecol. Indic. 2017, 77, 185-193. [CrossRef]

29. Wang, J.J. Agricultural eco-economic system coupling in Zhifanggou watershed in hilly-gully region of Loess Plateau. Chin. J. Appl. Ecol. 2009, 20, 2723-2729. (In Chinese)

30. Lv, X.; Liu, X. A study on the coupling Development of the Agricultural Land Eco-economic System: A case study of the Tarim River Basin in Xinjiang. Resour. Sci. 2010, 32, 1538-1543. (In Chinese)

31. Jian-Jun, Z.; Xiao-Ping, Z.; Ji-Jun, W.; Ming-De, H.; Jin-Peng, X. Coupling analysis of agro-ecolomic system in gully area of Loess Plateau in 1949-2008: A case study in Changwu County of Shaanxi Province. Chin. J. Appl. Ecol. 2011, 22, 755-762. (In Chinese)

32. Yulin City Statistics Bureau. Statistical Yearbook of Yulin City; China Statistics Press: Beijing, China, 2018.

33. Wang, S.J.; Fang, C.L.; Wang, Y. Quantitative investigation of the interactive coupling relationship between urbanization and eco-environment. Acta Ecol. Sin. 2015, 35, 2244-2254. (In Chinese)

34. Zhang, B.; Yang, Y.S.; Zepp, H. Effect of vegetation restoration on soil and water erosion and nutrient losses of a severely eroded clayey plinthudult in southeastern china. Catena 2004, 57, 77-90. [CrossRef]

35. Beaudoin, N.; Saad, J.K.; Laethem, C.V.; Machet, J.M.; Maucorps, J.; Mary, B. Nitrate leaching in intensive agriculture in northern france: Effect of farming practices, soils and crop rotations. Agric. Ecosyst. Environ. 2005, 111, 292-310. [CrossRef]

36. Luo, L.; Qin, L.; Wang, Y.; Wang, Q. Environmentally-friendly agricultural practices and their acceptance by smallholder farmers in china-A case study in xinxiang county, henan province. Sci. Total Environ. 2016, 571, 737-743. [CrossRef] [PubMed]

37. Guo, Z.; Shao, M. Impact of afforestation density on soil and water conservation of the semiarid loess plateau, china. J. Soil Water Conserv. 2013, 68, 401-410. [CrossRef]

(C) 2019 by the authors. Licensee MDPI, Basel, Switzerland. This article is an open access article distributed under the terms and conditions of the Creative Commons Attribution (CC BY) license (http://creativecommons.org/licenses/by/4.0/). 